\title{
ANALYSIS OF FORMING THIN TITANIUM PANELS WITH STIFFENERS
}

The growing demand for light and durable products has caused an increase in interest in products formed of thin sheets. In order to ensure sufficient stiffness of the drawn - parts, stiffening is often performed. Unfortunately, during the forming of stiffeners unwanted deformations of the drawn parts very often appear, which prevent them from further exploitation. In the paper, forming thin titanium panels with stiffeners is analysed. The panels are made of sheets of commercially pure titanium: Grades 2 , 3 and 4. In the results of numerical analyses which were performed using PamStamp 2G, taking into consideration the impact of the blank holder force and friction conditions on the strain distribution in the drawn parts, sheet thinning and springback values are presented. The numerical analysis results were compared with the experimental tests. It was concluded that in order to prevent panel deformation being a result of residual stresses, it is necessary to ensure adequate friction conditions on the contact surfaces between the deformed material and tools as well as a suitable blank holder force.

Keywords: commercially pure titanium, sheet, numerical simulation, sheet metal forming

\section{Introduction}

Titanium is one of the key metal materials used in the aviation industry. It is applied both as commercially pure titanium $[1,2]$ and titanium alloys [3-5]. Commercially pure titanium is used for less demanding structural components which are not required to be so highly mechanically strong, but are rather only expected to be light, resistant to corrosion and able to operate at high temperatures. Where high strength is required titanium alloys are used. Due to the growing tendency to reduce vehicle weight [6-9], especially aircraft weight, the demand for goods formed of sheet metal which replace heavy, monolithic cast products is growing. Because in aviation a significant number of components must be operated at high temperatures, such properties as heat and creep resistance are very desired. Shielding parts such as 'firewalls', whose main task is to isolate the engine from the rest of the airplane in the case of fire, must ensure the stability of the structural aircraft parts and protect the occupants from the effects of heat and flame for a sufficient time to conduct an emergency landing. According to [10], titanium sheets with a thickness of 0.016 inches is one of the materials approved for use without the need for special tests for creep and heat resistance. Unfortunately, forming products of such thin titanium sheets is one of the most difficult technological processes. It is connected with titanium's limited ability to plastically deform [11-15] and its high springback tendency [16] as well as low tribological properties [17-21]. Difficulties are encountered not only when forming sheet metal but also when joining. Neverthe- less, the decrease in construction weight would not be possible if not for the development in welding technologies such as electron and laser beam welding [22-27] of friction stir welding [28,29].

This paper is focused on analyzing the forming process of thin titanium panels with stiffeners. The panels are made of titanium sheets with a thickness of $0.4 \mathrm{~mm}$, which as mentioned are used for firewalls.

\section{Goal and scope of analyses}

An analysis of the possibility of cold forming thin titanium panels with stiffeners is the main goal of the work. The analysis includes forming panels of three grades of commercially pure titanium, whose chemical compositions are given in Table 1.

TABELA 1

Chemical composition of analysed titanium sheets

\begin{tabular}{|c|c|c|c|c|c|}
\hline \multirow{2}{*}{ Material } & \multicolumn{5}{|c|}{ Element content [\%] } \\
\cline { 2 - 6 } & $\mathbf{C}$ & $\mathbf{F e}$ & $\mathbf{N}$ & $\mathbf{O}$ & $\mathbf{T i}$ \\
\hline Grade 1 & $0.080 \div 0,008$ & $0.20 \div 0.04$ & $0.002 \div 0.050$ & $0.20 \div 0.07$ & rest \\
\hline Grade 2 & $0.007 \div 0,006$ & 0.14 & $0.006 \div 0.008$ & 0.1 & rest \\
\hline Grade 3 & $0.014 \div 0,016$ & $0.12 \div 0.13$ & $0.007 \div 0.01$ & 0.21 & rest \\
\hline
\end{tabular}

Numerical analyses were performed using the commercial program PamStamp 2G v.2012, specially dedicated for sheet metal working processes. The basic mechanical (yield strength $R_{e}$, tensile strength $R_{m}$, and elongation $A$ ) and technological prop-

\footnotetext{
* CZESTOCHOWA UNIVERSITY OF TECHNOLOGY, DABROWSKIEGO 69, 42-201 CZESTOCHOWA, POLAND

** FABRYKA NARZĘDZI MEDYCZNYCH CHIRMED, MSTOWSKA 8, 42-240 RUDNIKI K. CZĘSTOCHOWY, POLAND

\# Corresponding author: email: julita.winowiecka@gmail.com
} 
erties (hardening exponent $n$, Lankford coefficient $r$ ), which are necessary to carry out the numerical analysis, were determined experimentally in a static tensile test in accordance with [30]. In order to assess the correctness of the forming process, empirically determined forming limit diagrams (FLD) were used. The results of the numerical analyses were compared with those of the experimental process of forming a panel with two stiffeners, which is shown in Figure 1.

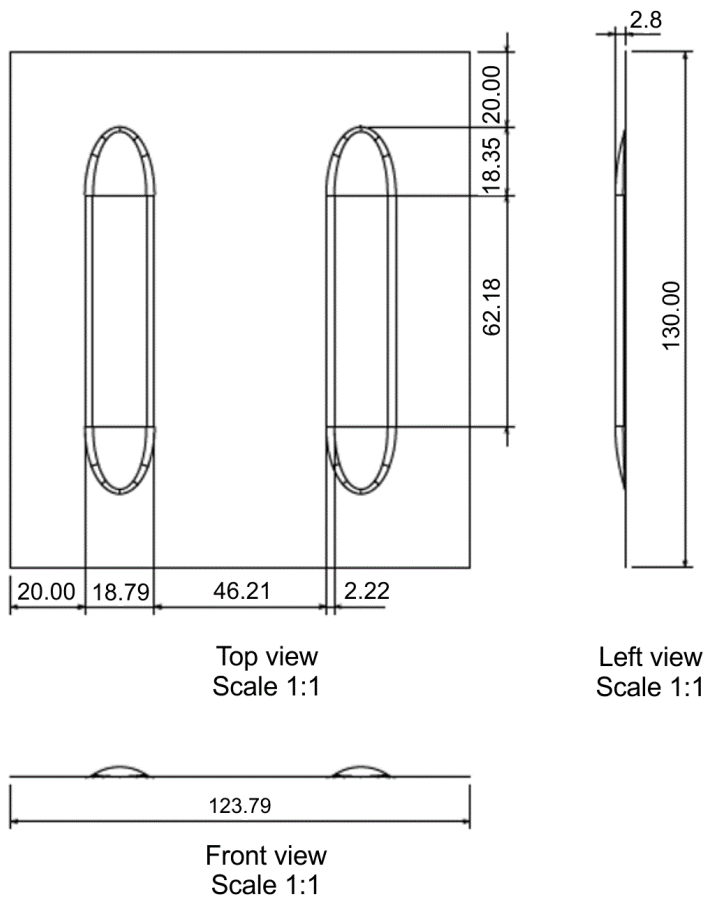

Fig. 1. Location, shape and dimensions of stiffeners in analysed panel

\section{Mechanical and technological properties of analysed titanium sheets}

Testing of the mechanical and technological properties was performed using the tensile testing machine ZWICK Z050. In order to take into consideration plastic anisotropy, three samples were cut from each grade sheet: Grade 2, Grade 3 and Grade 4 at 0,45 and $90^{\circ}$ to the rolling direction. The determined mechanical and technological properties are given in Table 2 .

The analysed titanium sheets are characterized by relatively significant planar anisotropy, which is presented in Figure 2.
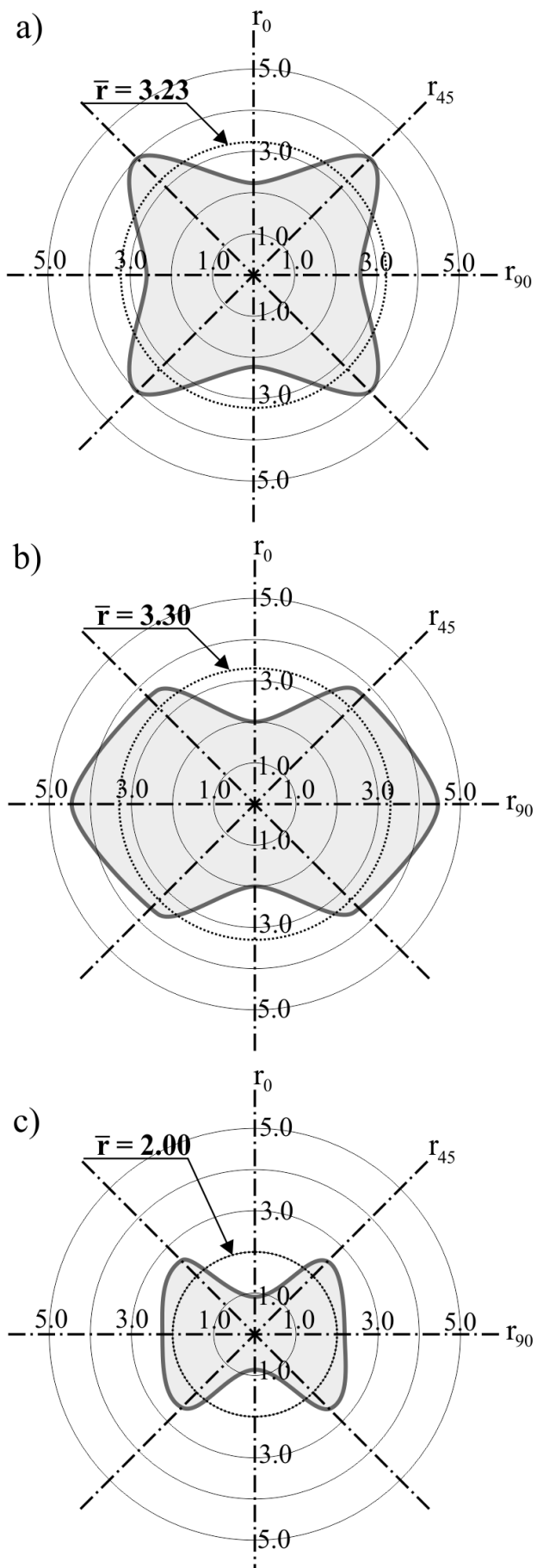

Fig. 2. $r$-value of titanium sheets in polar coordinate system: a) Grade 1, b) Grade 2, c) Grade 3

TABLE 2

Mechanical and technological properties of analysed titanium sheets

\begin{tabular}{|c|c|c|c|c|c|c|c|c|c|c|c|}
\hline & $K w,^{\circ}$ & $E$, GPA & $R_{p 0,2,}$ MPA & $R_{e H}$, MPA & $R_{e L}$, MPA & $R_{m}$, MPA & $F_{m}, \mathrm{kN}$ & $A_{q v}, \%$ & $A_{t}, \%$ & $K, \mathrm{MPa}$ & $n,-$ \\
\hline \multirow{3}{*}{ Gr 1} & 0 & 133.60 & 304.71 & - & - & 381.53 & 1.91 & 23.47 & 7.05 & 529.09 & 0.096 \\
\hline & 90 & 110.29 & 306.93 & - & - & 382.45 & 1.91 & 23.34 & 6.96 & 530.56 & 0.096 \\
\hline & 45 & 106.95 & 261.44 & - & - & 363.89 & 1.82 & 25.77 & 9.78 & 541.05 & 0.126 \\
\hline \multirow{3}{*}{ Gr 2} & 0 & 103.17 & 368.23 & - & - & 466.56 & 2.33 & 23.99 & 12.20 & 643.62 & 0.101 \\
\hline & 90 & 101.89 & 325.41 & - & - & 450.20 & 2.25 & 20.54 & 6.30 & 654.29 & 0.104 \\
\hline & 45 & 103.45 & 339.10 & - & - & 429.74 & 2.15 & 22.27 & 6.97 & 587.44 & 0.088 \\
\hline \multirow{3}{*}{ Gr 3} & 0 & 99.81 & 480.09 & - & - & 602.68 & 3.01 & 19.07 & 12.20 & 817.24 & 0.096 \\
\hline & 90 & 113.02 & - & 579.91 & 565.37 & 629.38 & 3.15 & 21.55 & 11.86 & 856.55 & 0.096 \\
\hline & 45 & 105.81 & - & 530.48 & 527.85 & 586.10 & 2.93 & 18.76 & 8.83 & 761.82 & 0.076 \\
\hline
\end{tabular}


All the analysed titanium sheets are characterized by a planar anisotropy coefficient of less than zero, falling in the range $\Delta r=11.162 \div-0.288$, which means that the potential forming of axisymmetric cylindrical drawn parts can lead to the creation of 'ears' at an angle of $45^{\circ}$ to the rolling direction. Due to the occurrence of planar anisotropy in all the analysed sheets, it is expected that during forming, non-uniform material flow in different directions to the rolling direction will appear. Therefore, in the case of asymmetrical shape and asymmetrical orientation of the stiffeners, this fact must be taken into consideration when cutting sheet metal.

On the other hand, due to the relatively high coefficient of normal anisotropy (greater than 1.5), it can be expected that the sheet will not be significantly thinned during the forming process and there will be no rupture.

According to the Erichsen cupping test, Grade 1 sheet is the most susceptible to plastic deformation, for which the $I E$ is $11.43 \mathrm{~mm}$, and the less susceptible to plastic deformation is Grade 3 sheet, for which the $I E$ is only $7.83 \mathrm{~mm}$.

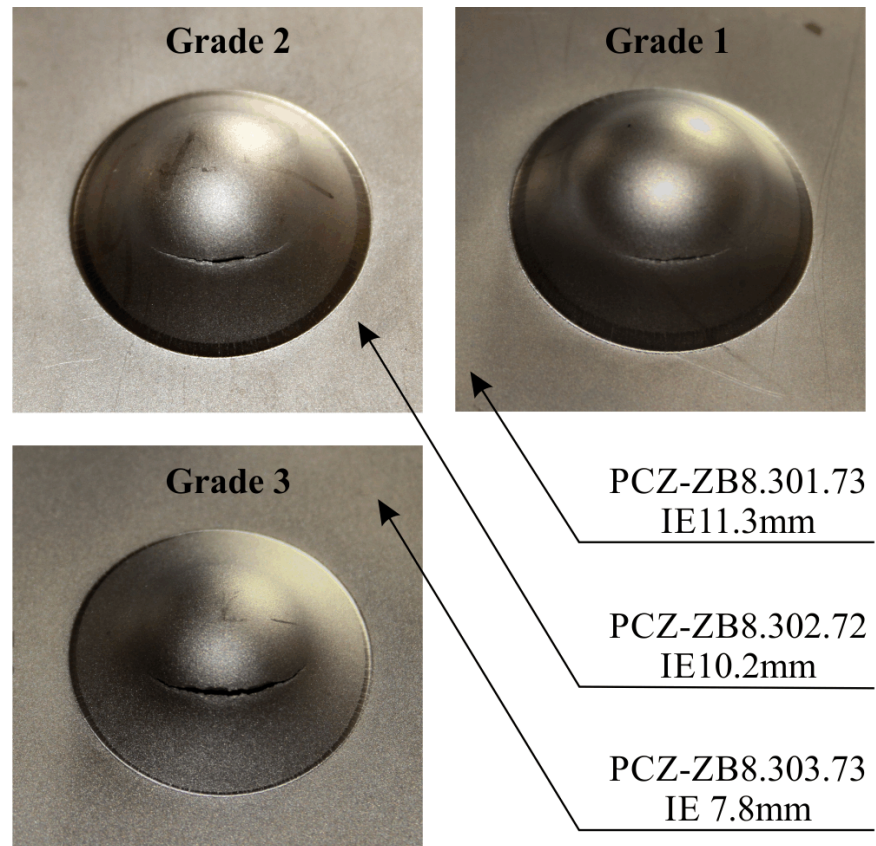

Fig. 3. Results of Erichsen cupping test

To predict the forming behaviour of the analysed sheets in the PamStamp 2G system, forming limit diagrams (FLDs) were determined. An FLD provides graphical interpretation of material effort in the major $\left(\varepsilon_{1}\right)$ and minor $\left(\varepsilon_{2}\right)$ strain coordinate systems (Fig. 4). Detailed description of determining FLDs is discussed in work [31].

The lowest values of strains from the FLDs are as follows: $\varepsilon_{1}=0.45$ for Grade 1 sheet, $\varepsilon_{1}=0.32$ for Grade 2 sheet and $\varepsilon_{1}=0.28$ for Grade 3 sheet. These values are significantly smaller than those reached by conventional drawing steel sheets used in sheet metal forming processes. This means that forming titanium sheets, particularly Grade 3 sheets in ambient temperature, will pose several problems.

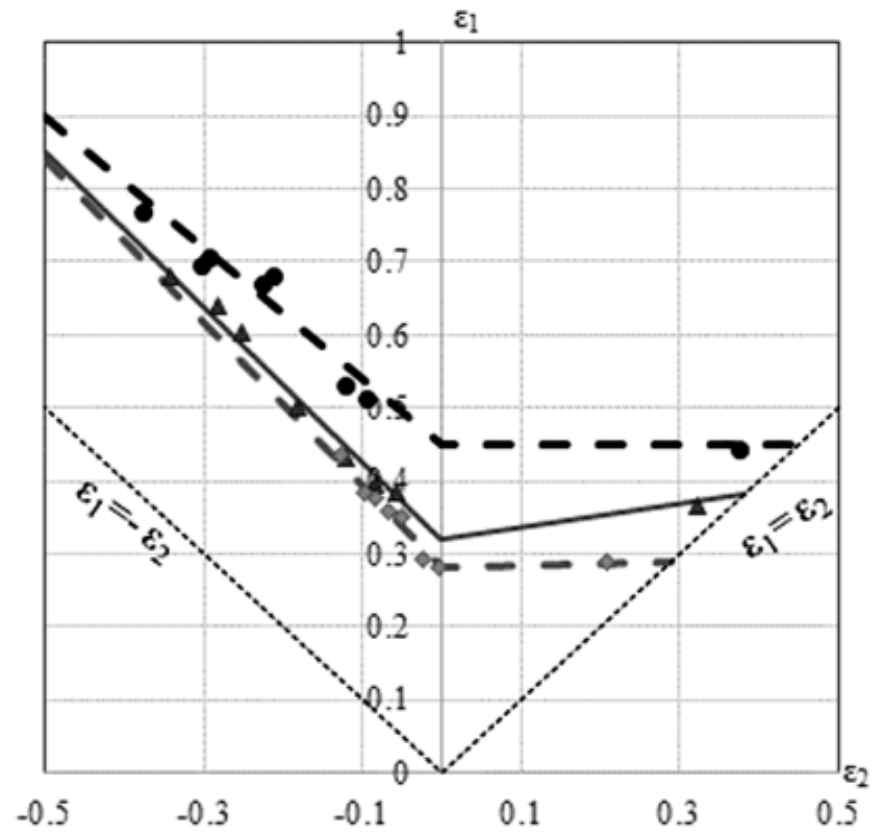

- Experimental Grade 1 - Theoretical Grade 1

- Experimental Grade 2 Theoretical Grade 2

- Experimental Grade 3 - - Theoretical Grade 3

Fig. 4. Forming limit diagrams for analysed sheets

\section{Numerical analysis of forming process of thin titanium panels with stiffeners}

Surface models of the forming tools (Fig. 5) were prepared using Catia v. 5, as IGES files, and then they were imported to the appropriate module of the PAMSTAMP 2G system. 4-node shell elements were applied for building up the tools and the sheet metal. Suitable boundary conditions were assigned to each piece of the tool, namely: the die was deprived of all degrees of freedom, the punch and the blank holder can move in the $Z$ direction thanks to the application of a velocity vector to the punch and a force to the blank holder. The sheet has all degrees of freedom. The plastically deformed materials (sheets) were defined as anisotropic ones based on the Hill'48 yield criterion. The material properties for the numerical models were assumed according to Table 2. The strain-stress curves for the analysed sheets were described according to Hollomon's law $\sigma=K \cdot \varepsilon^{n}$, where: $K$ - the material constant, $n$ - the strain hardening coefficient. The friction conditions between the tool and the deformed sheet were defined using the friction coefficients according to [18]. For dry conditions, the friction coefficient value was assumed as $\mu=0.4$ and for lubrication as $\mu=0.1$. The numerical analyses include the following configurations of friction coefficients:

(1) $\mu=0.1$ in the case of lubrication on all contact surfaces

(2) $\mu=0.4$ in the case of dry condition on all contact surfaces

(3) $\mu=0.1$ in the case of lubrication on the contact surface between the punch and deformed sheet and $\mu=0.4$ in the case of dry conditions on the contact surfaces: die - deformed material - blank holder. 


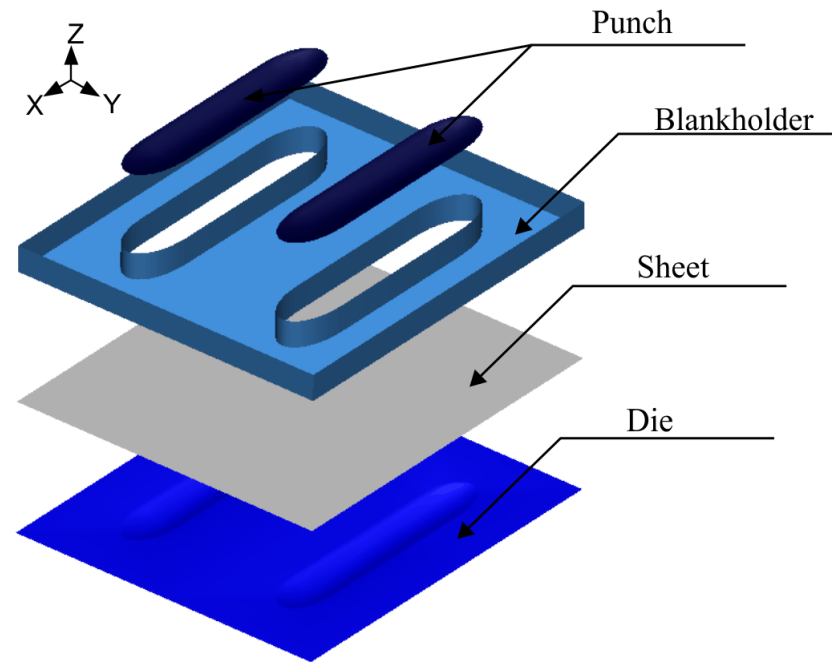

Fig. 5. Surface model of tool for forming thin-walled panel with two stiffeners
Moreover, in the numerical simulations, four values of blank holder force: 100, 200, 400 and $600 \mathrm{kN}$ were taken into consideration. The distribution and values of plastic strains, changes in the sheet thickness and the panel width after the forming process, as well as the springback after unloading were analysed. The numerical calculation results, for example for the drawn parts formed of Grade 1 titanium in dry conditions according to configuration (2), are presented in Figs 6-8.

With the increase in blank holder force, the thickness distribution in the drawn parts becomes more symmetrical (Fig. 6d). When $F_{d}=600 \mathrm{kN}$, the sheet thickness of the flat panel part is almost identical, and the thickness distribution of the sheet in the area of the stiffeners is almost the same on both stiffener sides (from the drawn part centre and its edges). The greater the blank holder force, the greater the thinning of the material in the area of the stiffeners. Material thinning is localized mainly at the base of the ribbing.

Thickness [mm]

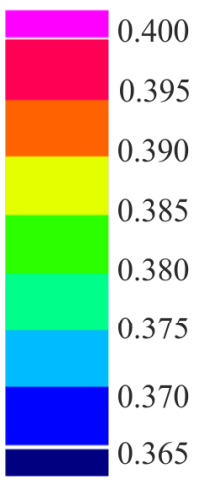

a)

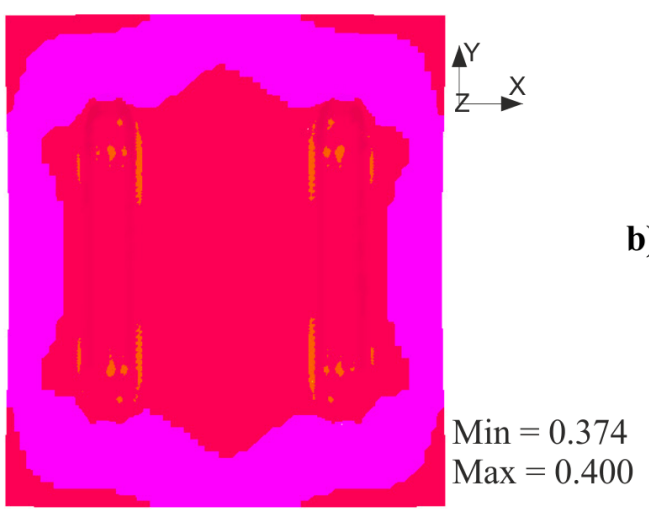

c)
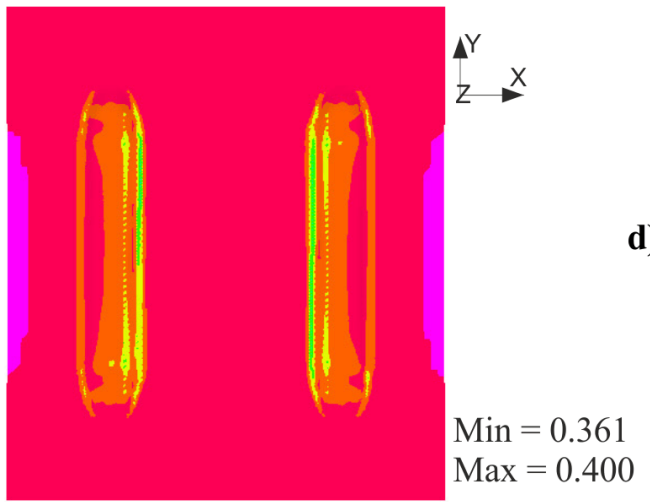

b)
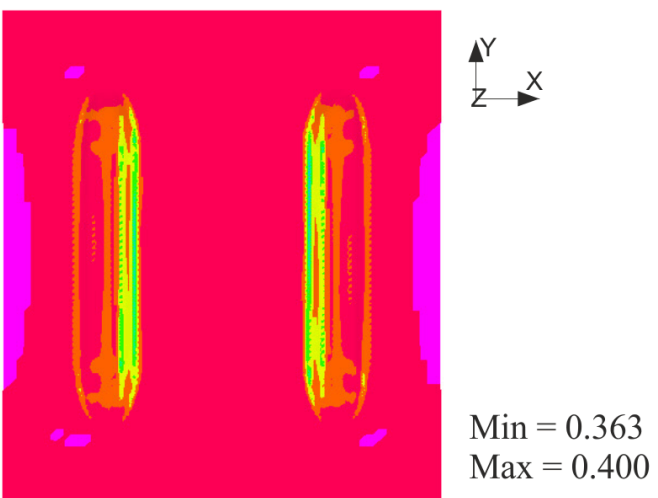

d)

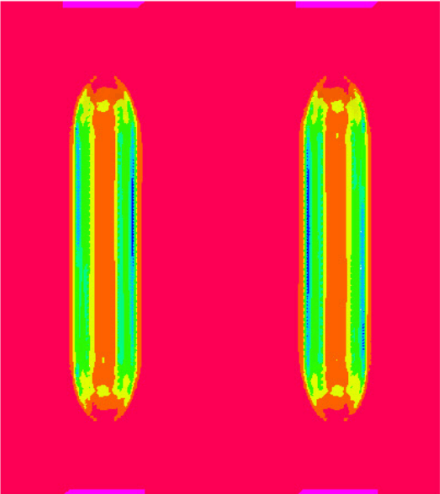

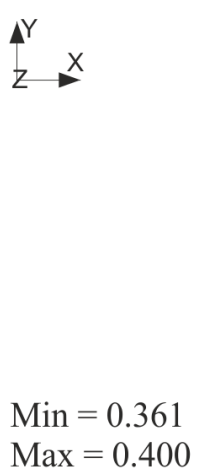

Fig. 6. Thickness distribution in panels made of Grade 1 titanium formed in dry conditions on all contact surfaces (configuration 2) with blank holder force: a) $F_{d}=100 \mathrm{kN}$, b) $F_{d}=200 \mathrm{kN}$, c) $F_{d}=400 \mathrm{kN}$, d) $F_{d}=600 \mathrm{kN}$

The maximum plastic strains range from 0.093 for $F_{d}=100 \mathrm{kN}$ (Fig. 7a) to 0.145 for $F_{d}=600 \mathrm{kN}$ (Fig. $7 \mathrm{~d}$ ). Greater plastic strains were observed for dry conditions in comparison to those observed in the case of forming with lubrication on all the contact surfaces. The stiffeners are more formed by stretching rather than drawing the material from the flat sheet metal part to the die cavity. Therefore, there is much less difference in the width of the start and end panel in comparison to the panel formed with lubrication on all the contact surfaces. When using a downforce $F_{d}=600 \mathrm{kN}$, panel narrowing is only $0.036 \mathrm{~mm}$, which will lead to smaller deformations of larger panels with a large number of stiffeners.

With an increase in blank holder force, there is a decrease in springback. A summary of the numerical analyses is given in Table 3. 


\section{Plastic strain [-]}

\begin{tabular}{|l|l|}
\hline & 0.140 \\
0.120 \\
0.100 \\
0.080 \\
0.060 \\
0.040 \\
0.020 \\
\hline & 0.000 \\
\hline
\end{tabular}

a)
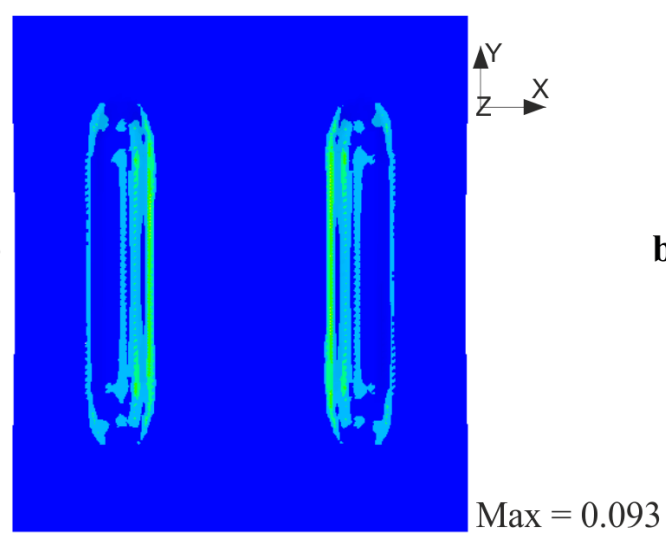

b)

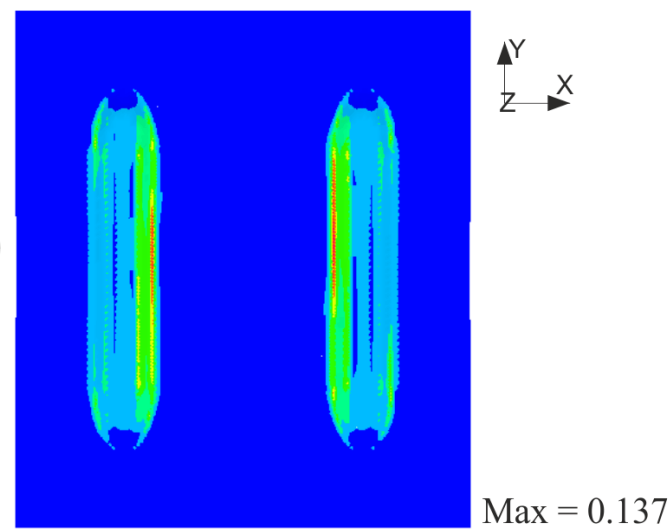

c)

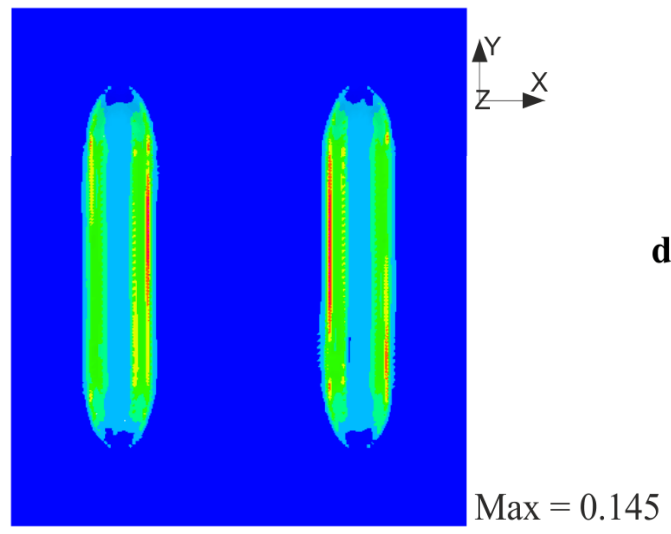

d)

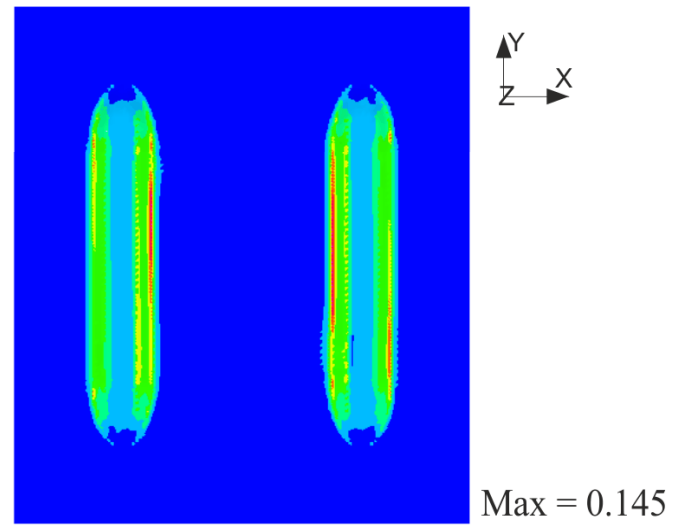

Fig. 7. Plastic strain distribution in panels made of Grade 1 titanium formed in dry conditions on all contact surfaces (configuration 2) with blank holder force: a) $F_{d}=100 \mathrm{kN}$, b) $F_{d}=200 \mathrm{kN}$, c) $F_{d}=400 \mathrm{kN}$, d) $F_{d}=600 \mathrm{kN}$

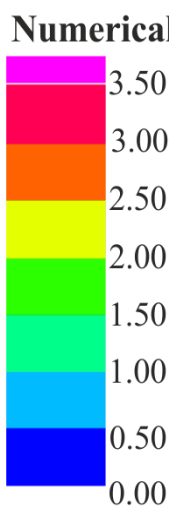

\section{a) between nodes [mm]}

a)
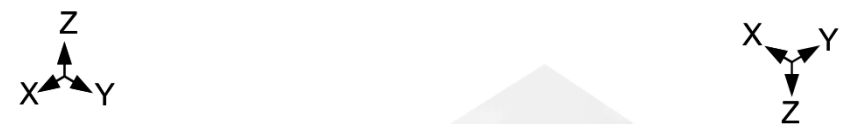

2.50
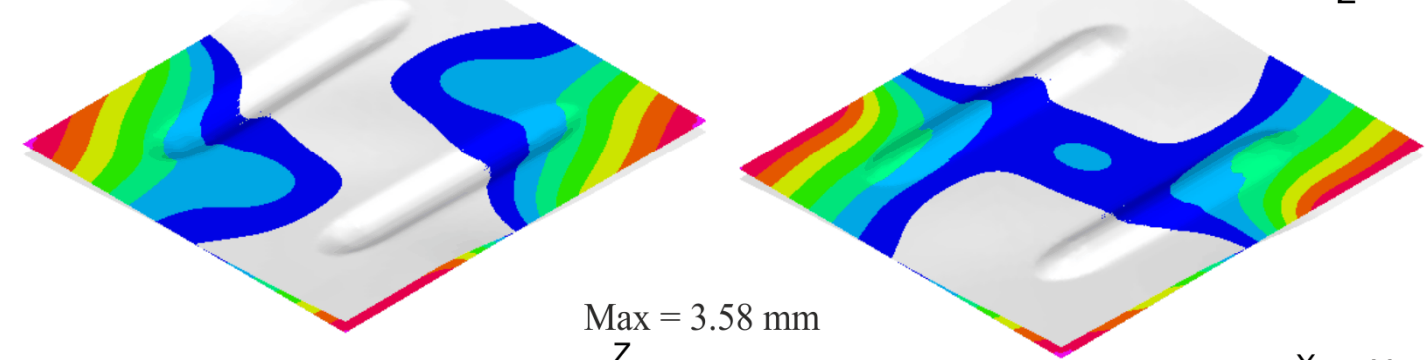

b)
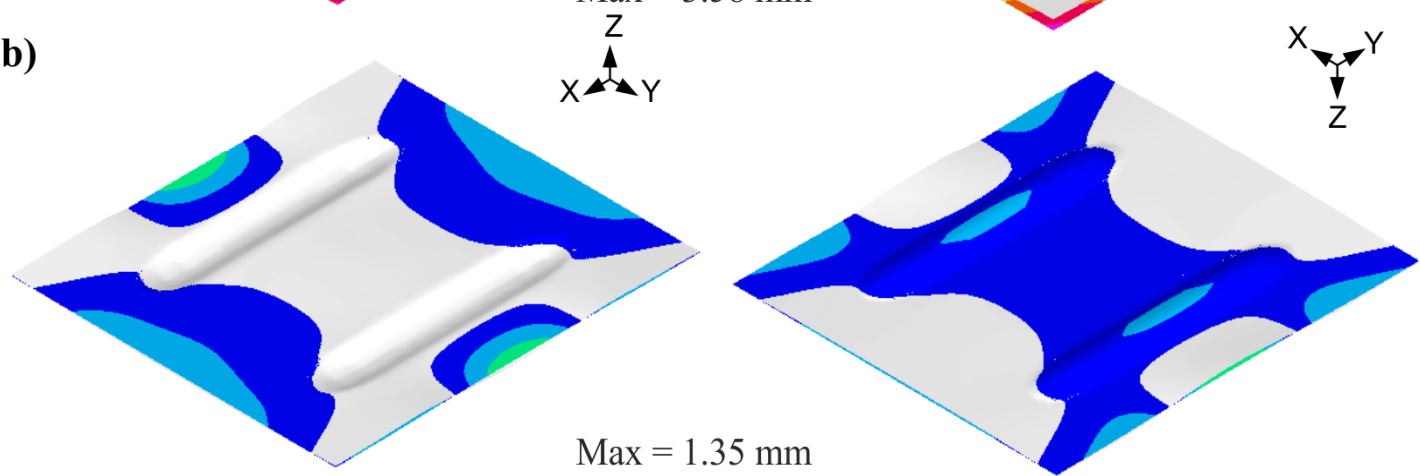

Fig. 8. Numerical distance between nodes in panels made of Grade 1 titanium formed in dry conditions on all contact surfaces (configuration 2) with blank holder force: a) $F_{d}=100 \mathrm{kN}$, b) $F_{d}=600 \mathrm{kN}$ 
Summary of numerical analyses of forming titanium panels with two stiffeners

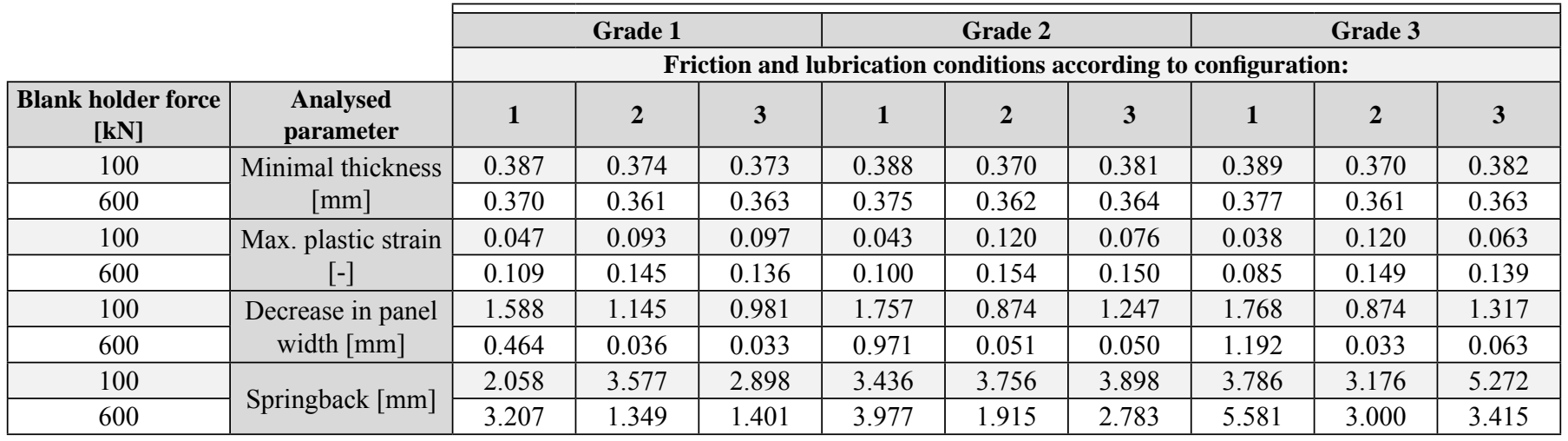

According to the analysis of the numerical results, the forming process of thin titanium panels is affected by many factors, hence each case of forming must be considered individually. The analyses show that the kind of deformed material has a decisive influence on the forming process. The mechanical properties (especially $R_{e}$ to $R_{m}$ ratio), which strongly depend on the chemical composition of the deformed material decide on the ability of the material to plastically deform. Although the study refers only to commercially pure titanium, even small quantities of impurities cause differences in the ability to plastically deform titanium sheets. Detailed analysis of the forming process showed that the blank holder force and frictional conditions on the contact surfaces between the tools and the deformed material play a particularly important role. The most adverse forming conditions occur during the sheet metal forming of panels with stiffeners using lubrication on all the contact surfaces. Then the material from the flat part of the panel is drawn into the die cavity; as a result there is a significant reduction in the width of the formed panel (Fig. 9) and as a consequence the high springback appears.

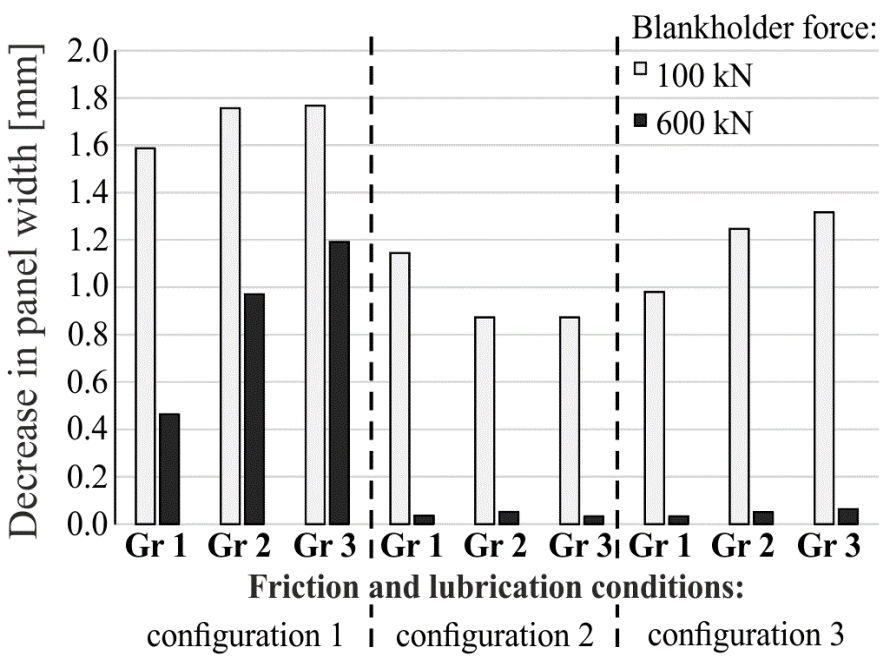

Fig. 9. Panel width reduction values resulting from forming stiffeners using blank holder force: $F_{d}=100 \mathrm{kN}$ and $F_{d}=400 \mathrm{kN}$
While lubrication on all the contact surfaces can be clearly defined as unfavourable forming conditions, forming in dry conditions or with lubrication on selected contact surfaces must be treated individually. The values of panel width reduction after forming, as well as springback, differ slightly. Thus, due to the fact that in practice it is difficult to ensure lubrication in the very small areas of stiffeners, it was assumed that in the experiments it would be sufficient to apply dry conditions on all the contact surfaces so that the formation of stiffeners takes place only by stretching, which in consequence will prevent warping and bending of the panels and in turn it will make panel assembly easier and reduce the sound effects accompanying the deformation of thin-walled panels.

\section{Experimental verification}

Verification of the numerical analyses was done on the basis of experiments in which titanium panels with two stiffeners were formed in dry conditions, i.e. according to configuration (3). The ARAMIS Digital Correlation Image System was used for verification. Before the forming process, the sheet metal surfaces were scanned to determine their flatness, i.e. to determine the actual distance of the sheet surface from the measuring plane. Then panel forming was performed. After the forming process the drawn parts were scanned again in order to determine the amount of springback. The method of measuring the deformation of the panel after its unloading is discussed in detail in [11]. The measurement results are shown in Figure 10.

Unfortunately, all the prepared sheet blanks were characterised by a deviation from flatness. For the samples made of Grade 1 titanium, the flatness deviations were in the range of $1.30 \div 1.95 \mathrm{~mm}$. The greatest flatness deviation as a result of springback after material unloading is on the edges of the formed panels. The average measured value of springback for the panels made of Grade 1 titanium is $1.42 \mathrm{~mm}$, while the calculated value is $1.35 \mathrm{~mm}$. It means that the results of the experimental and theoretical research differ by about $5 \%$. 
Flatness deviation of sheet $[\mathrm{mm}]$
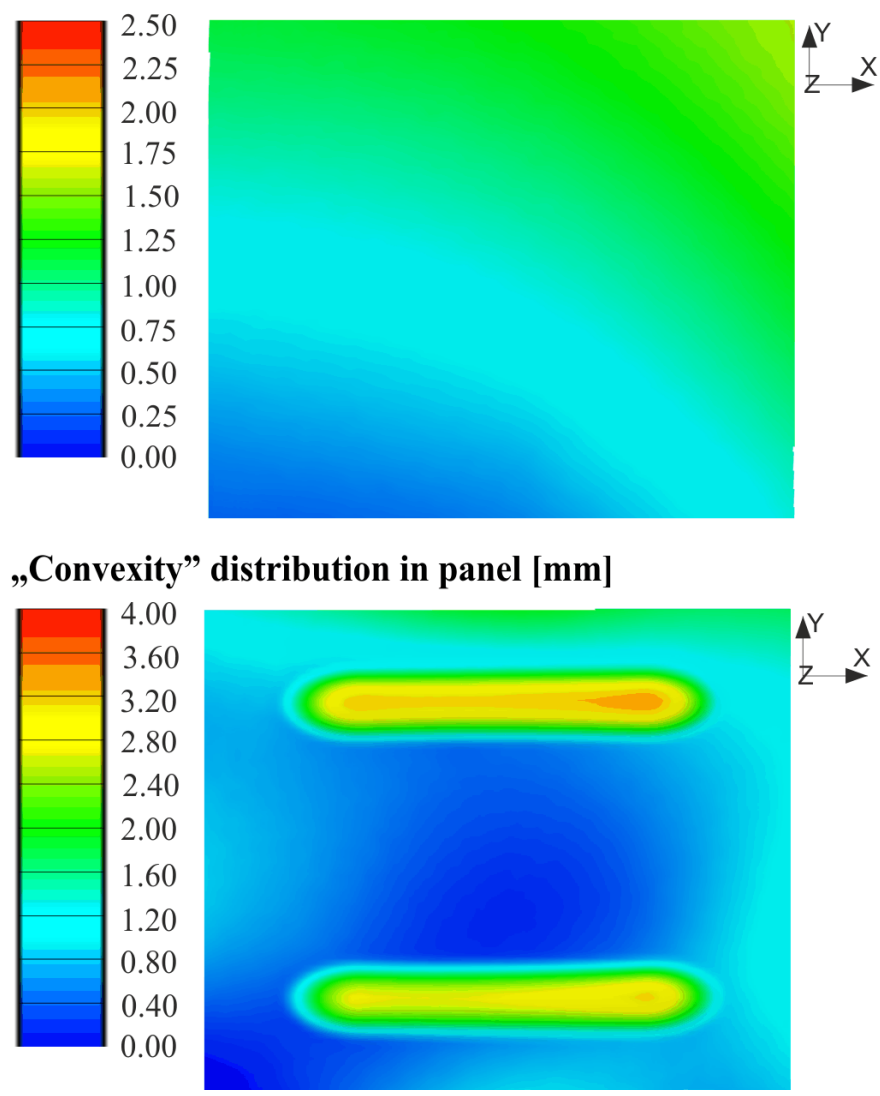

Fig. 10. Flatness deviations of initial blank (upper) and convexity distribution (bottom) for panel made of Grade 1 titanium (PCZ-ZB8-301.123)

\section{Conclusions}

- The forming process of thin titanium panels is dependent on many factors, and therefore each forming case must be considered individually. The kind of deformed material has a significant impact on the forming process. The mechanical properties, especially the $R_{e}$ to $R_{m}$ ratio, which strongly depends on the chemical composition of the deformed material, has a significant influence on sheet drawability. Grade 1 sheet has the highest drawability, but the lowest tensile strength among the three analysed commercially pure titanium grades.

- Springback significantly hinders producing a drawn part with complex geometry of good quality. Grade 3 titanium sheet showed the highest springback, while Grade 1 titanium sheet showed the lowest.

- The numerical simulations showed that the blank holder force and frictional conditions on the contact surfaces play an important role among the technological parameters of the sheet - metal forming process.

- The most unfavourable forming conditions occur when forming such thin-walled titanium panels with stiffeners using lubrication on all the contact surfaces. In this case, material from the flat part of the panel is drawn into the die cavity and therefore there is a decrease in panel width and in turn, high springback.
- The forming process should be performed with a high blank holder force and in dry conditions so that the stiffeners could be formed only by stretching, which in consequence will prevent warping and bending of the panels, and in turn it will make panel assembly easier and reduce the sound effects accompanying the deformation of thin-walled panels.

- In the case of panels made of Grade 1 titanium, the experimental verification showed good agreement with the springback obtained from the numerical calculations.

\section{Acknowledgements}

Financial support of Structural Funds in the Operational Programme - Innovative Economy (IE OP) financed from the European Regional Development Fund - Project 'Modern material technologies in aerospace industry', No POIG.01.01.02-00-015/08-00 is gratefully acknowledged.

\section{REFERENCES}

[1] J. Winowiecka, K. Adamus, Key Eng. Mat. 687, 250 (2016).

[2] N. Yi, T. Hama, A. Kobuki, H. Fujimoto, H. Takuda, Mat. Sci. Eng. A 655, 70 (2016).

[3] J.Adamus in: E. Onate, D.R.J. Owen, D. Peric, B. Suarez (Eds), Proceedings of the 12th Int. Conf. on Computational Plasticity. Fundamentals and Applications COMPLAS XII, Barcelona-Spain, 2013.

[4] C. Cui, B.M. Hu, L. Zhao, S. Liu, Mater. Design 32, 1684 (2011).

[5] H. Yang, X.G. Fan, Z.C. Sun, L.G. Guo, M. Zhan, Science China Technological Sciences 54/2, 490 (2011).

[6] E. Aghion, B. Bronfin, D. Eliezer, J. Mater. Process. Tech. 117, 381 (2001).

[7] R.R. Boyer, R.D. Briggs, J. Mater. Eng. Perform. 14, 681 (2005).

[8] T. Dursun, C. Soutis, Mater. Design 56, 862 (2014).

[9] J.C. Williams, Jr E.A. Starke, Acta Mater. 51, 5775 (2003).

[10] FAA Federal Aviation Regulations (FAR PART 23.1191).

[11] J. Adamus, P. Lacki, Meccanica 51 (2), 391 (2016)

[12] J. Adamus, P. Lacki, in: E. Oñate, D.R.J. Owen, D. Peric, M. Chiumenti (Eds) Proceedings of the 13th International Conference on Computational Plasticity - Fundamentals and Applications, COMPLAS XIII, Barcelona-Spain, CIMNE, 204, (2015).

[13] J. Adamus, P. Lacki, M. Motyka, K. Kubiak, in: Proceedings of the 12th World Conference on Titanium - Ti 2011, Science Press Beijing, China1 337 (2012).

[14] G. Ambrogio, L. Filice, F. Gagliardi, Mater. Design 34, 501 (2012).

[15] M. Nakai, M. Niinomi, J. Hieda, K. Cho, Y. Nagasawa, T. Konno, Y. Ito, Y. Itsumi, H. Oyama, Mater. Sci. Eng. A 594, 103 (2014).

[16] J. Adamus, P. Lacki, Comp. Mater. Sci. 50, 1305 (2011).

[17] S. Wang, Z. Liao, Y. Liu, W. Liu, Surf. Coat. Tech. 252, 64 (2014).

[18] J. Adamus, K. Dyja, W. Więckowski, Key Eng. Mat. 687, 163 (2016).

[19] J. Adamus, J.M. Lacker, Ł. Major: Arch. Civ. Mech. Eng. 13, 64 (2013).

[20] J. Ma, H. Yang, H. Li, D. Wang, W.-J. Li, Trans. Nonferrous Met. Soc. China 25, 2924 (2015). 
180

[21] K. Mori, T. Murao, Y. Harada, Transaction of the NAMRI/SME 30, 25 (2002).

[22] J. Adamus, P. Lacki, M. Motyka, Arch. Civ. Mech. Eng. 15 (1), 42 (2015).

[23] Lacki, K. Adamus, K. Wojsyk, M. Zawadzki, Key Eng. Mat. 473, 540 (2011).

[24] P. Lacki, in: E.Onate, D.R.J. Owen, D.Peric, B.Suarez (Eds), Proceedings of the 12th Int. Conf. on Computational Plasticity. Fundamentals and Applications COMPLAS XII, Barcelona-Spain, 2013.

[25] P. Lacki, K. Adamus, P. Wieczorek, Comp. Mater. Sci. 94, 17 (2014).

[26] E. Schubert, M. Klassen, C. Zerner, C. Walz, G. Seplod, J. Mater. Process. Tech. 115, 2 (2001)
[27] S.M.O. Tavares, Mater. Sci. Forum 8, 219 (2012).

[28] C. Bitondo, U. Prisco, A. Squillace, G. Giorleo, P. Buonadonna, G. Dionoro, G. Campanile, International Journal of Material Forming 3 (1), 1079 (2010).

[29] A. Derlatka, K. Kudła, K. Makles, in: $11^{\text {th }}$ World Congress on Computational Mechanics WCCM 2014, $5^{\text {th }}$ European Conference on Computational Mechanics ECCM 2014, $6^{\text {th }}$ European Conference on Computational Fluid Dynamics ECFD 2014, code 110475, 6807 (2014).

[30] PN-EN ISO 6892-1:2010P Metallic materials - Tensile testing Part 1: Method of test at room temperature.

[31] J. Winowiecka, P. Lacki: Calculation of the Forming Limit Curve for titanium grade 2 using modified geometry of samples. Computer Methods in Materials Science 15, 37 (2015). 